\title{
Influence of a patient information program on adherence and persistence with an aromatase inhibitor in breast cancer treatment - the COMPAS study
}

Volker Ziller ${ }^{1,2^{*}}$, loannis Kyvernitakis ${ }^{1,2}$, Dana Knöll ${ }^{1,2}$, Astrid Storch $^{1,2}$, Olaf Hars ${ }^{3}$ and Peyman Hadji ${ }^{1,2}$

\begin{abstract}
Background: It is known that suboptimal adherence rates may affect endocrine treatments for breast cancer, but little information has been reported whether any efforts to improve treatment adherence have been successful. We designed a randomized, controlled study to investigate the effect of oral or written patient information program on adherence and persistence when receiving an aromatase inhibitor (Al).

Methods: The study cohort included 181 female patients receiving an adjuvant Al treatment randomly assigned to one of three groups. The first group received reminder letters and information booklets, the second group was reminded and informed through telephone calls and the control group received neither. The primary endpoint was the rate at which patients were classified as adhering to treatment after twelve months.

Results: Baseline results showed a well-balanced randomization with no significant differences between groups. After 12 months, 48\% (Cl 35-62) of the control group, 62.7\% (Cl 49-75) in the telephone group and 64.7\% (Cl 51-77) in the letter group were adhering to therapy. A post hoc pooled analysis with a one-way hypothesis for both interventions versus control indicated a significant difference between the groups favouring the intervention $(p=0.039)$.

Conclusion: The aim of this study was to investigate the efficacy of a simple and practical interventional program in enhancing adherence to breast cancer treatment. Patients receiving additional/supplemental information appeared to have an improved adherence rate even though the differences between groups were not statistically significant for the primary endpoint.
\end{abstract}

Keywords: Adherence, Compliance, Aromatase inhibitors, Breast cancer, Endocrine treatment

\section{Background}

In past decades, breast cancer survival rates have increased substantially as a consequence of significant improvements in early diagnosis and the introduction of more effective treatments e.g. adjuvant endocrine therapies. Thirdgeneration aromatase inhibitors (AIs) such as anastrozole $(1 \mathrm{mg} / \mathrm{d})$, letrozole $(2.5 \mathrm{mg} / \mathrm{d})$, and exemestane $(25 \mathrm{mg} / \mathrm{d})$, have proven more effective than tamoxifen in upfront,

\footnotetext{
* Correspondence: ziller@med.uni-marburg.de

'Department of Gynecology, University hospital of Giessen and Marburg GmbH, Marburg, Baldingerstrasse, 35033 Marburg, Germany

${ }^{2}$ Department of Endocrinology, Reproductive Medicine and Osteoporosis, University hospital of Giessen and Marburg $\mathrm{GmbH}$, Marburg, Baldingerstrasse, 35033 Marburg, Germany

Full list of author information is available at the end of the article
}

switch and extended adjuvant treatments with regard to disease-free survival (DFS) and distant metastasis (DM) in postmenopausal women with hormone-sensitive early breast cancer [1-3]. However, patients only attain maximum benefits from their medications if they follow the instructions and adhere to dosing schedules [4]. As with other chronic diseases, patients with breast cancer often fail to take the correct dosage at the prescribed frequency and for the proper duration [5].

Awareness of poor patient adherence to treatment programs has led to investigation of this issue by an increasing number of clinical studies [6-9]. Due to the seriousness of their disease, cancer patients are (generally) considered highly motivated and compliant, but limited 
prospective data is available on their adherence to adjuvant treatment for breast cancer, and more specifically, regarding the use of aromatase inhibitors. Recent studies reported that up to $50 \%$ of patients stop taking their medication during the course of 5 year adjuvant treatment with tamoxifen, resulting in a significant increase in mortality [10]. It was also reported that a substantial proportion of patients on anastrozole fail to adhere to the recommended treatment after the first year. In a different report, only $49 \%$ of patients with breast cancer (BC) took adjuvant hormonal therapy for the full duration on the optimal schedule [11-16]. However, these studies were health care data based analyses and do not provide evidence about daily clinical routine treatment at the patients level [13]. We recently reported the results of a study using a combination of self-reporting and prescription refill counts in breast cancer patients taking daily tamoxifen or anastrozole. After 12 months of treatment, $80 \%$ of women on tamoxifen and $69 \%$ of women on anastrozole were adhering to treatment [17].

With a growing number of patients surviving breast cancer, the problem of adherence with therapy is becoming increasingly important $[13,18]$. Increased adherence and persistence are likely to improve patient outcomes, and COMPAS (Compliance in Adjuvant treatment of primary breast cancer Study) was designed to investigate the effects of frequent reminders that informed and motivated patients with respect to breast cancer and its treatment with an aromatase inhibitor. The aim of this study was to investigate the efficacy of a simple and practical intervention program on the ability of patients to stay on treatment with an aromatase inhibitor for the endocrine treatment of primary breast cancer.

\section{Methods}

\section{Objectives and definitions}

In the absence of a reliable treatment-specific maker, measuring patient adherence and persistence is a complex challenge that (in a real life setting) can only be achieved using surrogate endpoints. As it is impossible to control for every medication intake/application, patients need to be monitored by more or less crude subjective measurements as a generally accepted "gold standard" does not exist for measuring adherence and persistence. Following the definition of ISPOR (International Society for Pharmacoeconomics and Outcome Research), adherence is "the degree or extent of conformity to the recommendations about day-to-day treatment by the provider with respect to the timing, dosage, and frequency" [19]. Another way to measure adherence is to estimate persistence, which is defined as the duration of time from initiation to discontinuation of therapy $(8 ; 19)$. A patient is optimally adherent if no doses are missed, no extra doses are taken and no doses are taken in the wrong quantity or at the wrong time. A patient has optimal persistence if they take a medication as long as it is prescribed [20].

\section{Definition of adherence}

Adherence was defined as the percentage of a prescribed dose actually taken within a certain time frame. For this study the adherence after 12 and 24 months after therapy initiation was measured and we differentiated between self-reported adherence and prescription refill counts. Prescription refill counts were used to calculate the Medication Possession Ratio (MPR), which indicated the recommended prescriptions to actual prescriptions quotient. A patient was classified as adherent if selfreported adherence and an MPR of $80 \%$ or more was achieved. The limit of $80 \%$ was chosen based upon current literature [13,15,21-23]

\section{Definition of persistence}

Persistence was defined as the duration (in months) of therapy from initiation to discontinuation. Discontinuation was defined as no medication (refills/in possession) for at least 60 days or a discontinuation registered in the patient file for whatever reason (e.g. due to side effects).

\section{Measuring adherence and persistence}

This study aimed to investigate the everyday-life setting and only methods that did not stress or influence the patients were used.

To ensure these criteria, we combined two strategies:

1) Self-reported adherence using a specifically designed and standardized questionnaire in combination with an interview [17]. The questionnaire included 10 items concerning aromatase inhibitor tolerance, side effects, adherence and persistence. Furthermore, we added specifically designed questions that addressed side effects, patient's attitude towards breast cancer, their specific treatment, their knowledge about breast cancer and quality of life.

2) To add more objective criteria, we assessed prescription refills and calculated the medication possession ratio (MPR). Prescribed tablets were evaluated from hospital charts and prescription refill details (i.e. number of tablets prescribed, date of prescription, extra samples donated, etc.) from all physicians involved in the treatment of the patient (e.g. GP, Gynaecologist, Oncologist). To ensure the completeness of the data, the patient, hospital, GP, Gynaecologist and Oncologist were asked to provide information for any physician known to be involved in the prescribing process.

For the primary endpoint, these two measurements were combined and patients classified as adherent if both self-reporting and prescription refills indicated an adherence above $80 \%$. All interviews and the adherence 
classification were performed in a blinded manner, with interviewers and analysts not being informed about the randomization results.

\section{Design}

A single-centre, three-armed, randomized and partiallyblinded parallel group study was designed with the primary analysis at 12 and a secondary analysis planned for 24 months (not evaluated in this paper). Patients diagnosed with hormone receptor positive primary breast cancer that were recommended adjuvant treatment with an aromatase inhibitor were recruited. Diagnosis and treatment were initiated (independent of the study) according to German breast cancer guidelines by the local the interdisciplinary breast cancer tumour board which is part of the local comprehensive cancer centre. Study participation was offered to all patients that met the inclusion criteria.

\section{Intervention}

The intervention aimed to support patients in staying on treatment by reminding, informing and motivating them. Following the psychological principals of learning theory, and using variable, intermittent re-enforcement, the interventions were placed at doubling intervals during the first year. This approach was designed to achieve maximum effect with reasonable practicability. Interventions were planned for week 1, 2, 10, 20 and 33 in the first year (after start of therapy) and months 15, 18 and 21 in the second year (Figure 1).

Group 1 (Control group) - No intervention only standard information provided.
Patients received baseline information in the hospital and the 12 and 24 month interviews (visits).

Group 2 (Letter group) - Patients received a personalized motivational reminder letter, informative content in combination with a breast cancer information leaflet at 1, 2, 10, 20 and 33 weeks and at month 15, 18 and 21 .

Patients were addressed personally, reminded of the importance and impact of their disease, as well as the effects and possible side-effects of aromatase inhibitor (AI) treatment. Each letter included contact information and phone number for the study nurse available to answer questions as well as information for when the doctor should be contacted. The leaflet contained different breast cancer related topics such as "sport and cancer", "nutrition and cancer", etc.

Group 3 (Telephone group) - Patients were contacted by a study nurse at week 1, 2, 10, 20 and 33 and month 15, 18 and 21 via telephone. Employing a semi-structured interview technique, patients were reminded, informed and motivated during the phone call. The call aimed to provide individualized information, feedback to questions and problems with medication or provide contact with the treating oncologist if needed. Strategies were discussed that ensured the regular intake of the tablets ("what will you do to ensure you don't forget to take a tablet?", "Where will you keep the tablets?", etc.).

\section{Visits}

Patients were randomized to each group and baseline data recorded during the hospital stay for primary treatment. Specifically designed questionnaires were sent to each patient at 12 and 24 months in addition to a telephone

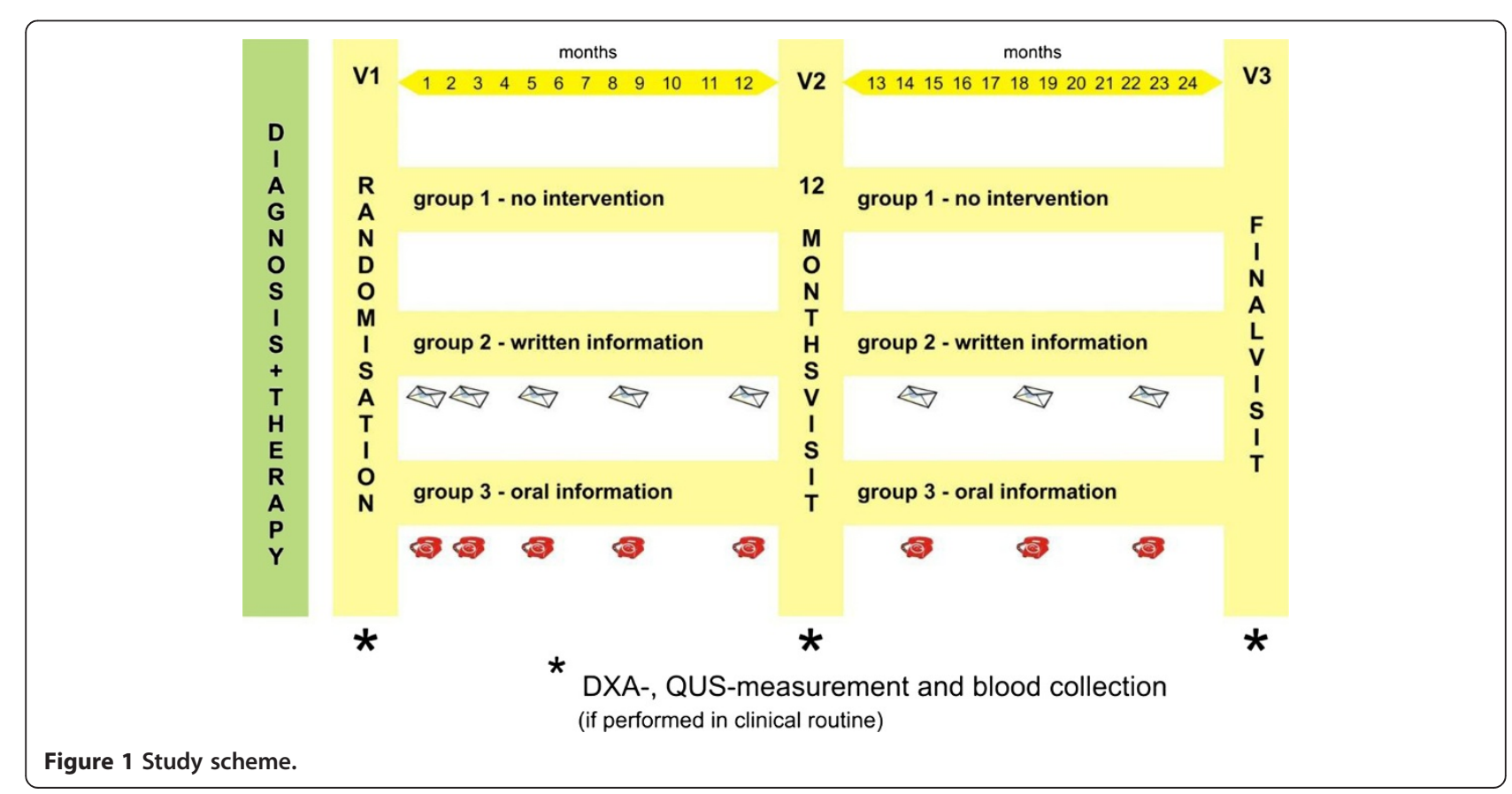


interview. Additionally other adherence related parameters and clinical questions were captured.

\section{Study population}

Between April 2006 and December 2008, all patients receiving aromatase inhibitor therapy as an adjuvant treatment for primary breast cancer, were screened for the study.

\section{Inclusion criteria:}

- Female

- Primary breast cancer

- Aromatase inhibitor therapy following German breast cancer guidelines [24].

- Informed consent

- Patient capable of using oral medication under their own initiative following prescribing information.

\section{Exclusion criteria}

- Continuously hospitalized, residing in a nursing home or receiving support via an ambulatory home care service (or similar service).

- Suffering from any form of dementia or similar disease interfering with memory.

- Other disease, mental or physical disorder that, in the opinion of the study coordinator, would have interfered with participation in the study.

- Known medical, drug or alcohol abuse.

\section{Primary and secondary analytic end points and planned analysis}

The primary endpoint for the analysis was the proportion of patients that could be classified "adherent" after 12 months according to pre-defined criteria. Adherence was further analysed by self-reported adherence and medication possession ratio. Secondary analysis evaluated persistence and future analyses are planned to analyse possible factors influencing adherence and persistence, reasons for non-adherence and discontinuation, influence of the interventions on other factors as knowledge of the disease and quality of life.

\section{Statistical analysis}

With a group size of 60 per arm (including a drop-out rate of $\sim 10 \%$ ), the study was designed to detect a minimum interventional effect of $30 \%$ with $\alpha=5 \%, 0.8$ power and two-way significance,

All analyses were performed using IBM-SPSS Version 17.0.

Descriptive analyses of the baseline characteristics, as well as testing normal distribution, were performed using the Kolmogorov-Smirnov-Test. Hypothesis testing was performed using Kruskal-Wallis, Chi-squared test or T-test/U-test (Mann-Whitney) where applicable. Wilcoxontesting was applied for time-dependent tests and KaplanMeier-Survival Analysis and Log Rank tests were used to calculate persistence.

\section{Ethics}

The study was conducted in accordance to the guidelines and with approval of the local ethics committee of the Philipps-University of Marburg.

\section{Results}

Patients (181) were recruited and randomized between April 3rd, 2006 and December 18th, 2008 (Figure 2) with a mean age at recruitment of 63.3 (SD 8.9). No significant differences were found in baseline characteristics with regards to age, BMI, tumour characteristics (TNM-Classification, grading, receptor-status), primary and adjuvant therapy, concomitant diseases, number of concomitant medications, profession and others (Table 1). Of these, 10 patients were excluded within four weeks of randomisation as they no longer met inclusion criteria (e.g. withdrew consent; 5 without providing a reason, 2 due to other serious disease, 2 due to starting an externally controlled treatment - home care service, 1 restarted menstruation just after randomisation and was switched to tamoxifen). No further follow-up was performed and they were counted as drop-outs.

The primary group endpoint revealed $48.0 \%$ (CI 35-62) of patients in the control group, $64.7 \%$ (CI 51-77) in the letter group and $62.7 \%$ (CI 49-75) in the phone group were classified as adherent after 12 months (Figure 3). The primary endpoint was comprised of self-reported adherence and prescription refill counts. For self reported

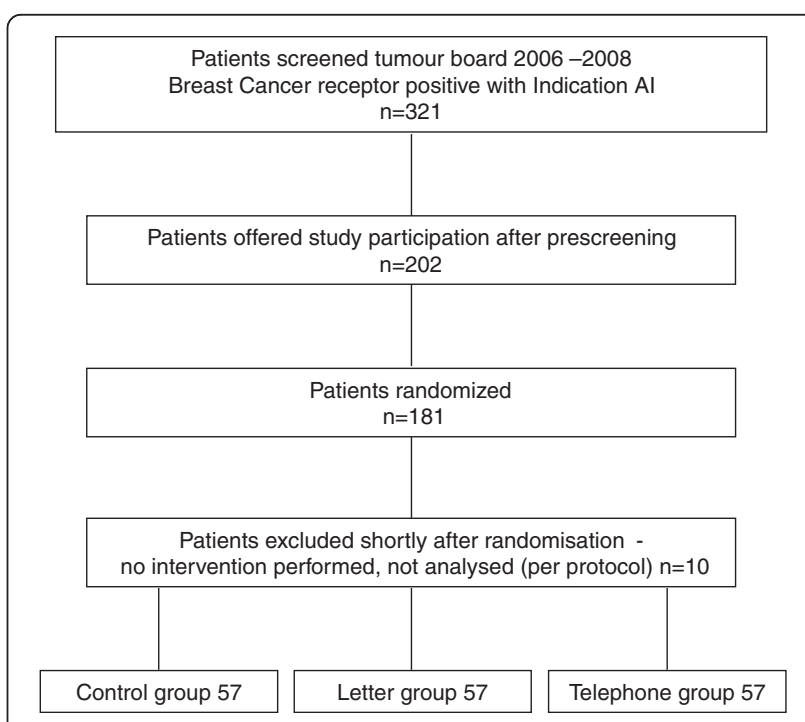

Figure 2 Consort diagram (12 month evaluation). 
Table 1 Baseline characteristics

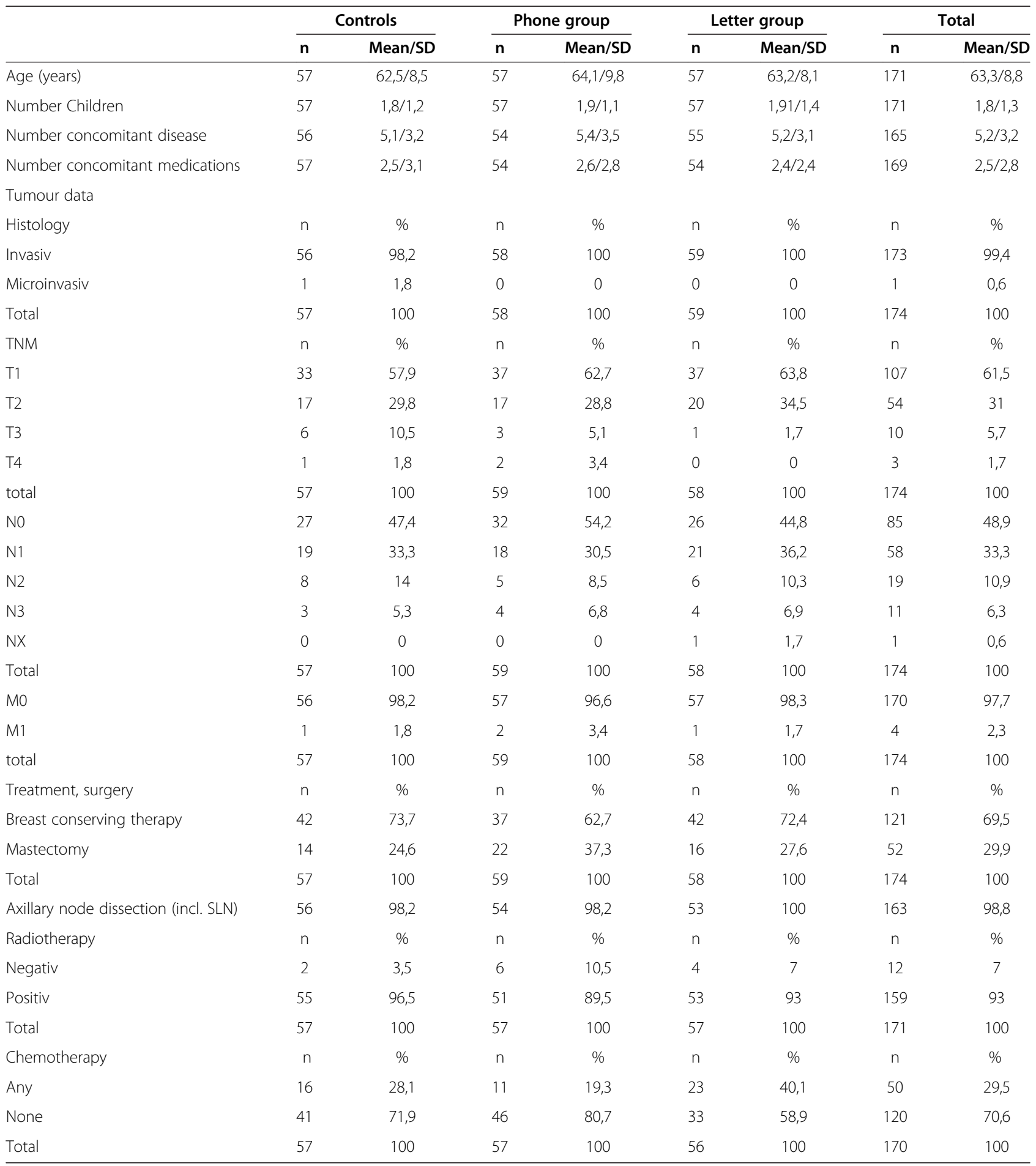

adherence alone, the analysis revealed $98.1 \%$ (CI 92-100), 94.3\% (CI 87-99) and 100\% (CI 96-100) adherent patients for controls, letter and phone group, respectively (Figure 3 ). Prescription refills (80\% cut-off) were achieved in 48\% (CI 35-62), 64.7\% (CI 51-76) and 62.7\% (CI 48-74) in the control group, letter group and phone group, respectively.
The differences between the groups did not reach statistical significance (Figure 3). A logistic regression analysis did not show any significant influence on adherence for $\mathrm{t}$ stage, nodal status, chemo- and radiotherapy and intervention group when entered as covariants in the model. To further analyse the trend seen for the primary endpoint 


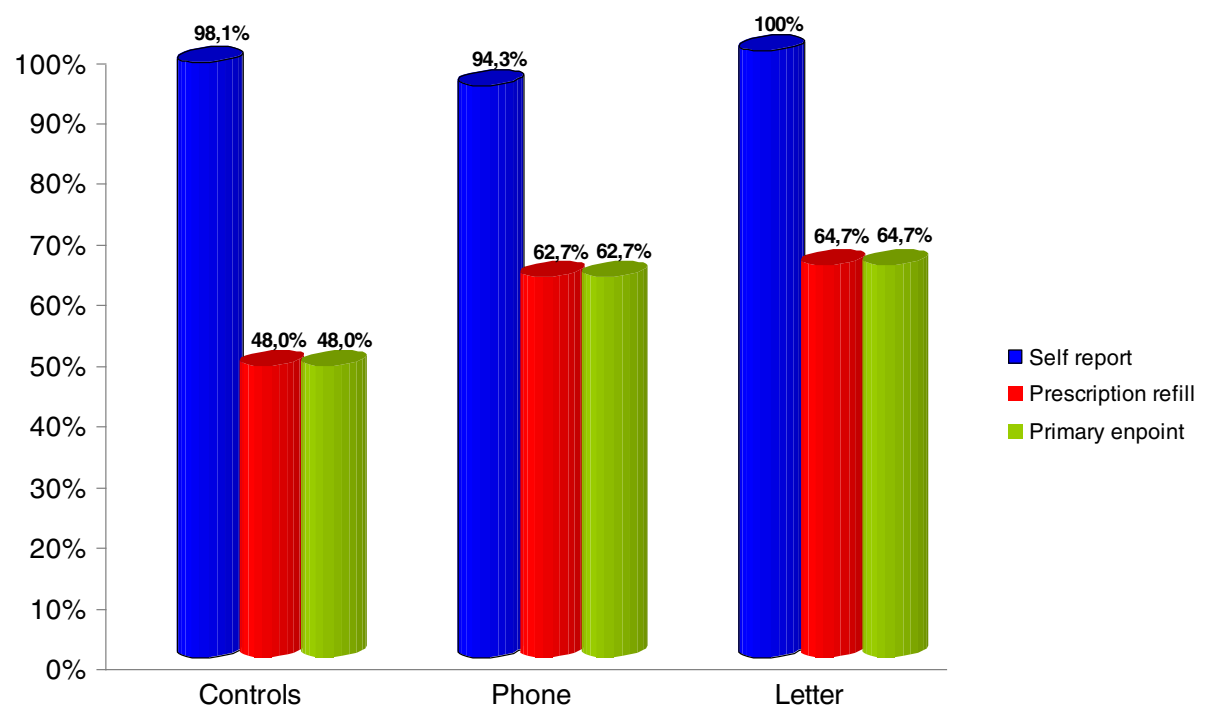

Figure 3 Rate of adherent patients: self report vs prescription refill vs prim endpoint (combined).

and to enhance the power of the analysis, a pooled analysis with a one-way hypothesis for both interventions versus control was performed. This post hoc testing indicated a significant difference between the groups $(\mathrm{p}=0.039)$.

Persistence was evaluated using Kaplan-Meyer Survival analysis and results are shown in Figure 4. The Log Rank (Mantel-Haenszel) Test showed no significance between intervention groups $\left(\chi^{2}=2.39 ; \mathrm{p}=0.305 ; \mathrm{df}=2\right)$. Discontinuation was only based on medication refill, in no case patient file information lead to further discontinuation events. Mean medication possession ratio and persistence is provided in Table 2. Mean Medication Possession Ratio (MPR) and persistence were not normally distributed by the Kolmogorov-Smirnov-Test. Overall significance between groups was tested using the Kruskal-Wallis-Test for MPR $\left(\chi^{2}=3.83 ; \mathrm{p}=0.147\right)$ and persistence $\left(X^{2}=5.01 ; \mathrm{p}=0.082\right)$. A U-Test (MannWhitney) for mean MPR did not reach statistical significance when comparing control and letter groups $(\mathrm{Z}=$ 1.85; $\mathrm{p}=0.064)$, no significance between control and phone groups $(Z=1.48 ; \mathrm{p}=0.145)$ and between intervention groups $(Z=0.44 ; p=0.660)$.

When mean persistence was analysed, the difference between control and letter groups $(Z=4.50 ; p=0.034)$ was significant, while no significant differences were found between control and phone groups $(Z=1.55 ; \mathrm{p}=$ $0.121)$ or between interventions $(Z=0.797$; $p=0.426)$.

Self reported global medication tolerance at the 12 month visit was bad or very bad in $23,6 \%$ of all patients (Table 3 ). Grouping was performed according to primary endpoint. When asked for reasons for interrupting treatment, $7.5 \%$ of all patients admitted forgetting to take the medication while
$68 \%$ of those with treatment gaps did so due to side effects. No significant differences were seen between groups.

\section{Discussion}

The well-established benefits of an adjuvant endocrine treatment with aromatase inhibitors can only be achieved if patients adhere to prescribed medications. A lack in adherence may lead to reduced clinical outcomes, unnecessary change of treatment, increased side effects or even higher hospitalisation rates due to treatment failure [20]. Despite the fact that women on adjuvant

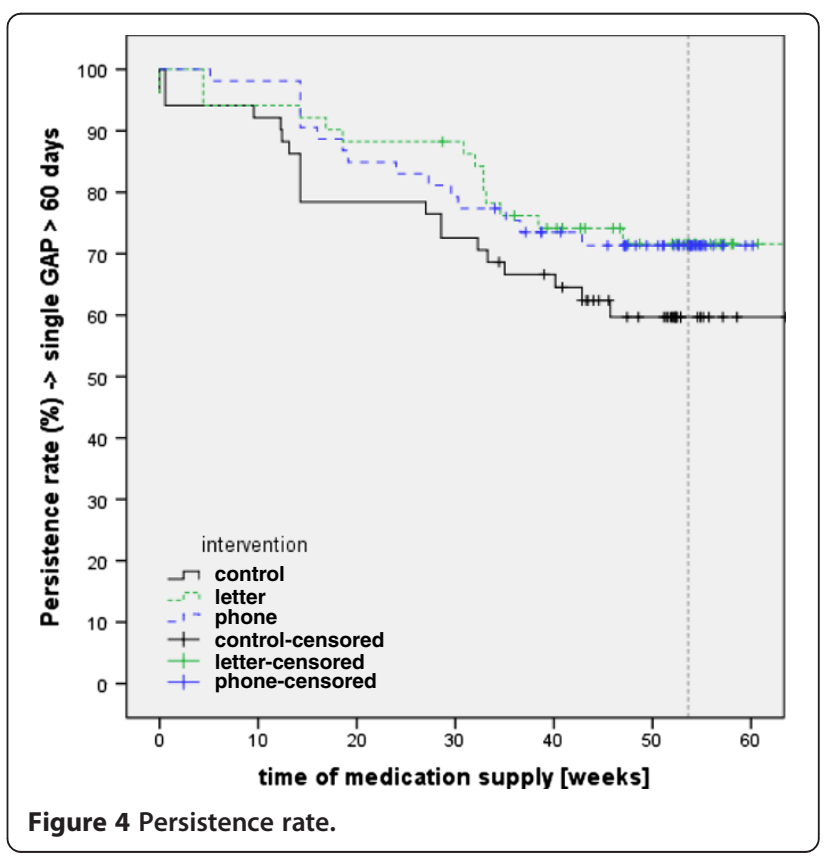


Table 2 Mean MPR and persistence

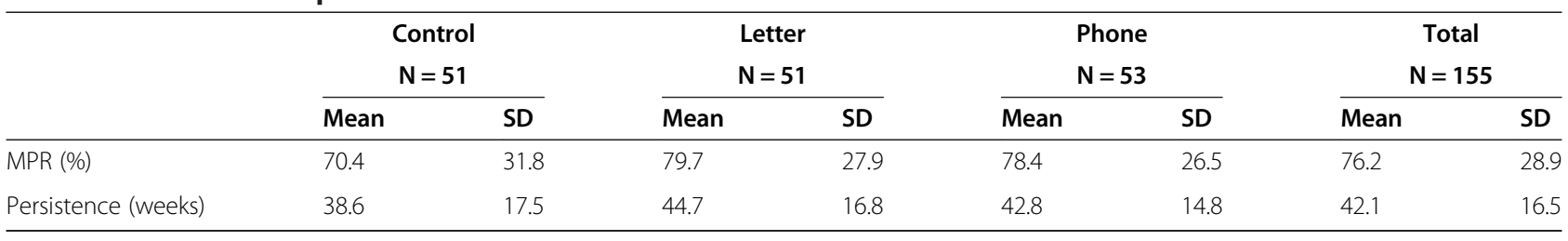

endocrine treatment for breast cancer are generally expected to be highly adherent as they are facing a serious life threatening disease, the treatment is effective, easy to use and generally well-tolerated, recent studies underline a clinically relevant decrease in adherence to tamoxifen and aromatase inhibitor therapy (including a reduction in cancer outcome) as soon as 12 months $[13,14,25]$. This indicated that patient statements and the doctors' perception with regards to adherence might not always reflect reality.

Waterhouse et al. compared self-reported adherence, classical pill count and the use of a micro electronic monitoring device (MEMS) in tamoxifen patients and found a significantly higher level of adherence was recorded by patient self-reporting when compared to MEMS (16.7\% vs. $29 \%$ non-adherence at 3 months) [16]. Other studies evaluating adherence to tamoxifen, using self-reported evaluation or database claim methods, found adherence rates ranging from $65 \%$ to $85 \%$ for different periods of follow-up [13,26-29]. Barron et al. demonstrated using prescription refill counts that by the end of follow-up at 3.5 years, the cumulative non-persistence rate had increased to $35.2 \%$ [30]. In an analysis by Partridge et al. within the used claim databases, the mean adherence to anastrozole significantly decreased from $78 \%-86 \%$ during the first year to $62 \%-79 \%$ during the third year [15]. The authors themselves, using the same methodology described for the COMPAS study comparing adherence and persistence to tamoxifen and anastrozole in the clinical practice, reported reduced adherence rates for the adjuvant treatment of breast cancer [17]. This served to illustrate the need for research to study and implement strategies helping patients to stay on medications and adhere to their treatment. However, improving

Table 3 Tolerance

\begin{tabular}{|c|c|c|c|c|c|c|}
\hline & \multicolumn{2}{|c|}{ Non-compliant } & \multicolumn{2}{|c|}{ Compliant } & \multicolumn{2}{|c|}{ Total } \\
\hline & $\mathrm{N}$ & $\%$ & $\mathrm{~N}$ & $\%$ & $\mathbf{N}$ & $\%$ \\
\hline Very bad & 9 & 14.3 & 9 & 10.1 & 18 & 11.8 \\
\hline Bad & 10 & 15.9 & 8 & 9.0 & 18 & 11.8 \\
\hline Indifferent & 13 & 20.6 & 29 & 32.6 & 42 & 27.6 \\
\hline Good & 21 & 33.3 & 27 & 30.3 & 48 & 31.6 \\
\hline Very good & 10 & 15.9 & 16 & 18.0 & 26 & 17.1 \\
\hline Total & 63 & 100.0 & 89 & 100.0 & 152 & 100.0 \\
\hline
\end{tabular}

adherence to aromatase inhibitor medication/treatment is a complex and challenging issue that has not been sufficiently studied [21].

We developed the COMPAS study in order to evaluate the clinical efficacy of two simple/viable interventions for improving adherence to adjuvant treatment with an aromatase inhibitor in breast cancer patients. These interventions provided a multifaceted approach to improved knowledge of the disease, treatment advantages and disadvantages in addition to explanations and solutions for the patient. The semi-structured interview style of the phone call from health professionals is designed to enhance the effects by using elements of motivational interviewing [31-33].

To measure adherence/persistence with a combination of self-reported information and prescription refill counts was a practical and fairly objective way to assess adherence in a real-life setting. The evaluation of the baseline characteristics showed a well-balanced randomization and a representative sample structure of the investigated patients while the baseline demographic characteristics of our real-life sample were comparable to study populations in pivotal aromatase inhibitor trials with regard to age, tumour characteristics and primary therapy [1-3]. They also show that the German guidelines for treatment initiation had been followed as suggested [24].

Evaluation of the primary endpoint revealed marked differences between the groups, even though the differences did not reach statistical significance. The authors are convinced there was a clinically significant effect for the interventions as demonstrated by the numerical increase for both interventions. Additionally, after pooling the intervention groups, a significant difference could be found in mean persistence. This cannot be taken as a final proof of concept, but should encourage the development of further interventions and studies containing a greater number of patients.

Kaplan-Meyer analysis for persistence showed that after one year a marked number of patients had discontinued treatment. There was a slight but statistically insignificant improvement due to the interventions. The reasons for non-adherence and non-persistence were diverse and the authors believe that only interventions that address multiple issues in the patients everyday life would lead to significant improvements. 
Several publications have linked tolerance to adherence [13]. The COMPAS study showed a positive side-effect profile, with $49.7 \%$ of patients reporting good or very good tolerance to their aromatase inhibitor

Non-adherent patients had slightly lower tolerance, but the difference was not statistically significant. There were no differences in the rate of patients that stopped treatment due to tolerance issues. Furthermore no other baseline parameters showed significant associations to adherence outcome. From the patients view, remembering to take the medication did not seem to be an issue as only $7.5 \%$ reported "forgetting" to take the tablets. Interventions that could enhance adherence would need to specifically address individual problems that occurred over time and due to individual habits, side effect(s), coping strategies, health belief and others.

\section{Conclusions}

COMPAS was designed to use personalized, multifaceted approaches to support numerous patients with a viable cost effective approach. Even so, the effects on adherence and persistence were not as significant as expected. Assisting patients with taking their medications should improve therapeutic outcome and efficiency, which would be of upmost importance to the individual, therefore further scientific effort is needed to reach those aims.

\section{Competing interests}

Professor Hadji has received honoraria from Astra Zeneca, Pfizer and Novartis as a consultant/advisor.

The other authors have nothing to disclose.

\section{Authors' contributions}

VZ \& PH conceived of the study, participated in its design and coordination, drafted the manuscript and made substantial contributions to analysis and interpretation of data. IK participated in the design of the study, made substantial contributions to acquisition of data and helped to draft the manuscript. DK \& AS made substantial contributions to acquisition of data and helped to draft the manuscript. $\mathrm{OH}$ participated in the design of the study and performed the statistical analyses. All authors read and approved the final manuscript.

\section{Acknowledgements}

This study was sponsored by an unrestricted research grand by Astra Zeneca Germany. We like to thank Prof. Dr. H.-H. Müller for his support with the statistical plan and study design.

\section{Author details}

'Department of Gynecology, University hospital of Giessen and Marburg GmbH, Marburg, Baldingerstrasse, 35033 Marburg, Germany. ${ }^{2}$ Department of Endocrinology, Reproductive Medicine and Osteoporosis, University hospital of Giessen and Marburg GmbH, Marburg, Baldingerstrasse, 35033 Marburg, Germany. ${ }^{3}$ Olaf Hars Statistical Consulting, Berlin, Germany.

Received: 21 January 2013 Accepted: 22 August 2013

Published: 4 September 2013

\section{References}

1. Coombes RC, Hall E, Gibson LJ, Paridaens R, Jassem J, Delozier T, Jones SE, Alvarez I, Bertelli G, Ortmann O, Coates AS, Bajetta E, Dodwell D, Coleman RE, Fallowfield LJ, Mickiewicz E, Andersen J, Lonning PE, Cocconi G, Stewart A, Stuart N, Snowdon CF, Carpentieri M, Massimini G, Bliss JM, et al: A randomized trial of exemestane after two to three years of tamoxifen therapy in postmenopausal women with primary breast cancer. $N$ Engl J Med 2004, 350(11):1081-1092.

2. Howell A, Cuzick J, Baum M, Buzdar A, Dowsett M, Forbes JF, Hoctin-Boes G, Houghton J, Locker GY, Tobias JS: Results of the ATAC (arimidex, tamoxifen, alone or in combination) trial after completion of 5 years' adjuvant treatment for breast cancer. Lancet 2005, 365(9453):60-62.

3. Thurlimann B, Keshaviah A, Coates AS, Mouridsen H, Mauriac L, Forbes JF, Paridaens R, Castiglione-Gertsch M, Gelber RD, Rabaglio M, Smith I, Wardley A, Price KN, Goldhirsch A: A comparison of letrozole and tamoxifen in postmenopausal women with early breast cancer. N Engl J Med 2005, 353(26):2747-2757.

4. Balkrishnan $\mathrm{R}$ : The importance of medication adherence in improving chronic-disease related outcomes: what we know and what we need to further know. Med Care 2005, 43(6):517-520.

5. Hadji P: Improving compliance and persistence to adjuvant tamoxifen and aromatase inhibitor therapy. Crit Rev Oncol Hematol 2010, 73(2):156-166

6. Hadji P, Body JJ, Aapro MS, Brufsky A, Coleman RE, Guise T, Lipton A, Tubiana-hulin M: Ann Oncol: Practical guidance for the management of aromatase inhibitor-associated bone loss; 2008.

7. Krueger KP, Felkey BG, Berger BA: Improving adherence and persistence: a review and assessment of interventions and description of steps toward a national adherence initiative. J Am Pharm Assoc (Wash DC) 2003, 43(6):668-678

8. Osterberg L, Blaschke T: Adherence to medication. N Engl J Med 2005, 353 (5):487-497

9. Rosenow EC III: Patients' Understanding of and compliance with medications: the sixth vital sign? Mayo Clin Proc 2005, 80(8):983-987.

10. Dezentje VO, van Blijderveen NJ, Gelderblom H, Putter H, van Herk-Sukel MP, Casparie MK, Egberts AC, Nortier JW, Guchelaar HJ: Effect of concomitant CYP2D6 inhibitor use and tamoxifen adherence on breast cancer recurrence in early-stage breast cancer. J Clin Oncol 2010, 28(14):2423-2429.

11. Fallowfield L: Acceptance of adjuvant therapy and quality of life issues. Breast 2005, 14(6):612-616.

12. Hershman DL, Kushi LH, Shao T, Buono D, Kershenbaum A, Tsai WY, Fehrenbacher L, Lin GS, Miles S, Neugut Al: Early discontinuation and nonadherence to adjuvant hormonal therapy in a cohort of 8,769 early-stage breast cancer patients. J Clin Oncol 2010, 28(27):4120-4128.

13. Murphy CC, Bartholomew LK, Carpentier MY, Bluethmann SM, Vernon SW: Adherence to adjuvant hormonal therapy among breast cancer survivors in clinical practice: a systematic review. Breast Cancer Res Treat 2012, 134(2):459-478.

14. Partridge $A H$, Wang PS, Winer EP, Avorn J: Nonadherence to adjuvant tamoxifen therapy in women with primary breast cancer. J Clin Oncol 2003, 21(4):602-606.

15. Partridge AH, Lafountain A, Mayer E, Taylor BS, Winer E: Asnis-alibozek a. Adherence to initial adjuvant anastrozole therapy among women with early-stage breast cancer. J Clin Oncol 2008, 26(4):556-562.

16. Waterhouse DM, Calzone KA, Mele C, Brenner DE: Adherence to oral tamoxifen: a comparison of patient self-report, pill counts, and microelectronic monitoring. J Clin Oncol 1993, 11(6):1189-1197.

17. Ziller V, Kalder M, Albert US, Holzhauer W, Ziller M, Wagner U, Hadji P: Adherence to adjuvant endocrine therapy in postmenopausal women with breast cancer. Ann Oncol 2009, 20(3):431-436.

18. Hershman DL, Shao T, Kushi LH, Buono D, Tsai WY, Fehrenbacher L, Kwan M, Gomez SL, Neugut Al: Early discontinuation and non-adherence to adjuvant hormonal therapy are associated with increased mortality in women with breast cancer. Breast Cancer Res Treat 2011, 126(2):529-537.

19. Cramer JA, Roy A, Burrell A, Fairchild CJ, Fuldeore MJ, Ollendorf DA, Wong PK: Medication compliance and persistence: terminology and definitions. Value Health 2008, 11(1):44-47.

20. Ruddy $\mathrm{KJ}$, Partridge $\mathrm{AH}$ : Adherence with adjuvant hormonal therapy for breast cancer. Ann Oncol 2009, 20(3):401-402.

21. Haynes RB, Montague P, Oliver T, McKibbon KA, Brouwers MC, Kanani R: Interventions for helping patients to follow prescriptions for medications. Cochrane Database Syst Rev 2000, 2, CD000011.

22. ISPOR: International society for pharmacoeconomics and outcomes research tenth annual international meeting contributed presentation abstracts. Value Health 2005, 8(3):237-419. 
23. World Health Organisation: Adherence to Long-Term Therapies: Evidence for Action ISBN. WHO-Publications; 2003. ISBN 9241545992.

24. Albert US, Altland H, Duda V, Engel J, Geraedts M, Heywang-Kobrunner S, Holzel D, Kalbheim E, Koller M, Konig K, Kreienberg R, Kuhn T, Lebeau A, Nass-Griegoleit I, Schlake W, Schmutzler R, Schreer I, Schulte H, Schulz-Wendtland R, Wagner U, Kopp I: Summary of the updated stage 3 guideline for early detection of breast cancer in Germany 2008. Rofo 2008, 180(5):455-465.

25. Partridge AH: Non-adherence to endocrine therapy for breast cancer. Ann Oncol 2006, 17(2):183-184.

26. Demissie S, Silliman RA, Lash TL: Adjuvant tamoxifen: predictors of use, side effects, and discontinuation in older women. J Clin Oncol 2001, 19(2):322-328.

27. Fink AK, Gurwitz J, Rakowski W, Guadagnoli E, Silliman RA: Patient beliefs and tamoxifen discontinuance in older women with estrogen receptor-positive breast cancer. J Clin Oncol 2004, 22(16):3309-3315.

28. Lash TL, Fox MP, Westrup JL, Fink AK, Silliman RA: Adherence to tamoxifen over the five-year course. Breast Cancer Res Treat 2006, 99(2):215-220

29. Owusu C, Buist DS, Field TS, Lash TL, Thwin SS, Geiger AM, Quinn VP, Frost F, Prout M, Yood MU, Wei F, Silliman RA: Predictors of tamoxifen discontinuation among older women with estrogen receptor-positive breast cancer. J Clin Oncol 2008, 26(4):549-555.

30. Barron TI, Connolly R, Bennett K, Feely J, Kennedy MJ: Early discontinuation of tamoxifen: a lesson for oncologists. Cancer 2007, 109(5):832-839.

31. Dilorio C, McCarty F, Resnicow K, McDonnell HM, Soet J, Yeager K, Sharma $S M$, Morisky DE, Lundberg B: Using motivational interviewing to promote adherence to antiretroviral medications: a randomized controlled study. AIDS Care 2008, 20(3):273-283.

32. Golin CE, Earp J, Tien HC, Stewart P, Porter C, Howie L: A 2-arm, randomized, controlled trial of a motivational interviewing-based intervention to improve adherence to antiretroviral therapy (ART) among patients failing or initiating ART. J Acquir Immune Defic Syndr 2006, 42(1):42-51.

33. Schmaling KB, Afari N, Blume AW: Assessment of psychological factors associated with adherence to medication regimens among adult patients with asthma. J Asthma 2000, 37(4):335-343.

doi:10.1186/1471-2407-13-407

Cite this article as: Ziller et al:: Influence of a patient information program on adherence and persistence with an aromatase inhibitor in breast cancer treatment - the COMPAS study. BMC Cancer 2013 13:407.

\section{Submit your next manuscript to BioMed Central and take full advantage of:}

- Convenient online submission

- Thorough peer review

- No space constraints or color figure charges

- Immediate publication on acceptance

- Inclusion in PubMed, CAS, Scopus and Google Scholar

- Research which is freely available for redistribution

Submit your manuscript at www.biomedcentral.com/submit
(O) Biomed Central 